\title{
Flexible sigmoidoscopy or colonoscopy as a screening modality for colorectal adenomas in older age groups? Findings in a cohort of the normal population aged $63-72$ years
}

\author{
E Thiis-Evensen, G S Hoff, J Sauar, B M Majak, M H Vatn
}

\begin{abstract}
Background-Most cases of colorectal cancer originate from adenomas. Removing adenomas has been shown to reduce the incidence of colorectal cancer. The design of cost effective endoscopic screening programmes requires a knowledge of the distribution of adenomas in different age groups.

Aim-To investigate the distribution of colorectal adenomas in older age groups in the normal population.

Method-A total of 356 men and women selected randomly from the population register were offered a colonoscopic screening examination to detect and remove polyps.

Results-In all, 241(68\%) subjects, mean age 67.4 years (range 62-73), attended. The caecum was intubated in $193(80 \%)$, and in this group $32(38 \%)$ women and 51 $(47 \%)$ men had adenomas. One hundred and ten $(54 \%)$ of the adenomas and 11 $(39 \%)$ of the "high risk adenomas" (adenomas larger than $10 \mathrm{~mm}$ in diameter, adenomas containing villous components, and adenomas with severe dysplasia) were found proximal to the sigmoid colon. In 36 $(43 \%)$ of the subjects with adenomas, the adenomas were only found proximal to the sigmoid colon. Twenty two (11\%) subjects had more than two adenomas. Of 203 adenomas discovered, $189(93 \%)$ were less than $10 \mathrm{~mm}$ in diameter.

Conclusion-More than half of the adenomas were localised proximal to the sigmoid colon, and, in nearly half of the adenoma bearing subjects examined, the adenoma was proximal to the descending colon. This indicates that a sigmoidoscopic screening examination in this age group would miss a substantial number of adenomas, but this may be acceptable as the vast majority of proximal adenomas do not progress to clinical cancer within the life expectancy of this age group. (Gut 1999;45:834-839)
\end{abstract}

Keywords: adenoma; colon; colorectal neoplasms; endoscopy; epidemiology; polyps

Correspondence to: Dr E Thiis-Evensen, Department of Medicine, Telemark Sentralsjukehus, N-3710, Skien, Norway.

Accepted for publication 23 June 1999
Colorectal cancer is one of the leading causes of death from malignant disease in the western world. As many as $60-90 \%$ of cases of colorectal cancer are believed to develop from colorectal adenomas. $^{1-4}$ The average time for malignant transformation of an adenoma is estimated to be 10-15 years. ${ }^{15}$ It should therefore be possible to remove an adenoma before it develops into overt cancer. Adenomas seldom give rise to symptoms and most of them are incidental findings during a clinical investigation or screening procedure. Endoscopic screening of asymptomatic persons has therefore been advocated as a means of reducing the incidence of colorectal cancer. Several screening modalities exist. Colonoscopy is the ideal, but it is expensive, time consuming, and requires highly trained endoscopists. Sigmoidoscopy is cheaper, better tolerated, and can be performed by specially trained technicians. ${ }^{6-8}$ Uncontrolled cohort and case-control studies indicate that endoscopy screening and polypectomy may reduce the incidence of colorectal cancer by $76-90 \% . .^{59-11}$ Which screening modality to choose depends on the distribution of adenomas in the colon of the population to be screened as well as acceptability (safety, compliance, cost, and availability of trained personnel). Most of our knowledge of adenoma distribution is based on autopsy studies ${ }^{12-15}$ and studies on subjects being examined because of symptoms or as part of a health care programme. ${ }^{16-19}$ Autopsy studies have shown that the distribution of adenomas changes from predominantly left sided (distal) to right sided (proximal) localisation with increasing age, ${ }^{13-15} 20$ indicating that sigmoidoscopy may not be an ideal screening modality for older age groups.

This study was performed to examine whether a screening programme based on sigmoidoscopy would discover the majority of adenomas in a normal population, aged 63 to 72 years, randomly selected from the population register.

\section{Attendees and methods}

ATTENDEES

In 1983 a randomised controlled prospective study of the effect of polypectomy on the incidence of colorectal cancer was started in the county of Telemark, Norway. ${ }^{21}$ Four hundred men and women were selected from the population register and offered a flexible sigmoidoscopy screening examination. A further 399 subjects were drawn from the same register and enrolled as a control group. These subjects were not given any attention until 1996, when all survivors in both the screening group and the control group were invited to have an endoscopic examination with polypectomy on detection of polyps. ${ }^{11}$ A press conference, 
which resulted in much publicity, was held before a letter of invitation was mailed to enrolled participants. One reminding letter was sent to those who did not respond. Only subjects from the control group in whom the caecum was successfully intubated were subjected to analysis in this paper.

ENDOSCOPIC EXAMINATION

The attendees were given the choice of a flexible sigmoidoscopic examination or a full colonoscopic examination, the latter being recommended. All examinations except one were performed by the same endoscopist (E T-E). The bowel was cleansed by intake of only transparent liquids on the day before the examination, followed by 4 litres of a polyethylene glycol solution taken orally in the afternoon on the day before the examination. For those preferring sigmoidoscopy, bowel cleansing was limited to a single $240 \mathrm{ml}$ sorbitol enema (Klyx) given 30 minutes before the endoscopic examination. A full medical and family history was recorded. A polyp was defined as a macroscopically elevated lesion of the mucosa irrespective of size, and was measured either by a scaled probe introduced through the biopsy channel of the endoscope, or with the biopsy forceps with the fully opened instrument equivalent to $9 \mathrm{~mm}$. Polyps measuring $4-5 \mathrm{~mm}$ or more in diameter were subjected to polypectomy by diathermy snare whereas tissue specimens from smaller polyps were obtained with cold biopsy forceps. When more than $5-10$ small polyps $(1-2 \mathrm{~mm})$ were found in the rectum, we aimed to sample at least two thirds of them. The localisation of each polyp was registered in centimetres from the anal verge

Table 1 Characteristics of subjects screened for colorectal polyps $(n=241)$

\begin{tabular}{llll}
\hline & $\begin{array}{l}\text { Caecum intubated } \\
(n=193)\end{array}$ & $\begin{array}{l}\text { Caecum not } \\
\text { intubated }(n=48)\end{array}$ & $p$ Value \\
\hline Mean (range) age (y) & $67(63-72)$ & $64.4(63-72)$ & 1.0 \\
Men & $109(56)$ & $21(44)$ & 0.2 \\
Women & $84(44)$ & $27(56)$ & \\
Median (range) body mass index $\left(\mathrm{kg} / \mathrm{m}^{2}\right)$ & $25(16-36)$ & $24.2(16-36)$ & 0.03 \\
Atherosclerotic disease & $31(16)$ & $8(17)$ & 0.9 \\
Diabetes mellitus & $7(4)$ & $1(2)$ & 0.9 \\
Inflammatory bowel disease & $4(2)$ & 0 & 0.7 \\
Previously diagnosed CRC & $4(2)$ & $1(2)$ & 1.0 \\
Previously diagnosed non-colorectal cancer & $5(3)$ & 0 & 0.6 \\
Current smoker & $44(23)$ & $17(35)$ & 0.1 \\
Past smoker & $62(32)$ & $10(21)$ & 0.2 \\
First degree relative with CRC & $14(7)$ & $3(6)$ & 1.0 \\
Abdominal complaints† & $47(24)$ & $10(21)$ & 0.7 \\
Previous non-study colonoscopy & $27(14)$ & $8(16)$ & 0.8 \\
\hline
\end{tabular}

Data for those in whom the caecum was successfully intubated during the examination are compared with the data for those in whom the caecum was not intubated. Numbers represent subjects $(\%)$ if nothing else stated.

^Includes coronary heart disease, intermittent claudication, and cerebrovascular accidents. Includes constipation, irritable bowel syndrome, loose stools, diarrhoea, pain, flatulence, haemorrhoids, mucus in the stools, and anal pruritus, either isolated or in combination.

CRC, colorectal cancer.

Table 2 Findings of polyps of all types, adenomas and high risk adenomas in subjects in whom the caecum was intubated at screening colonoscopy

\begin{tabular}{llll}
\hline & Women $(n=84)$ & Men $(n=109)$ & Total $(n=193)$ \\
\hline Polyps $^{\star}$ & $56(67)$ & $86(79)$ & $142(74)$ \\
Adenomas & $32(38)$ & $51(47)$ & $83(43)$ \\
High risk adenomas $\dagger$ & $12(14)$ & $13(12)$ & $25(13)$ \\
Significant finding $\neq$ & $16(19)$ & $20(18)$ & $36(19)$ \\
\hline
\end{tabular}

Values represent number of subjects (\%)

^Including adenomas, hyperplastic polyps, mucosal tags, one carcinoid, and one angiolipoma. tAdenoma $\geqslant 10 \mathrm{~mm}$ in diameter and/or villous components and/or severe dysplasia.

$\ddagger$ High risk adenoma and/or three or more adenomas irrespective of size, dysplasia or villous components. for those in the rectum and sigmoid colon, and in colonic segments proximal to this. A proximal lesion was defined as a lesion proximal to the sigmoid/descending colonic junction. This definition was chosen because this is an anatomical landmark usually recognisable at a sigmoidoscopic examination, and this area is also usually cleansed after a small enema given immediately before the examination. No sedation or analgesia was used except for in one participant who insisted and was given $3 \mathrm{mg}$ midazolam intravenously as premedication.

\section{BIOLOGICAL MATERIAL}

Polyps were fixed in formaldehyde for routine histological examination. All polyps were examined by the same experienced pathologist (B M), using the WHO classification. ${ }^{22}$ Dysplasia was graded as mild, moderate, or severe. Adenomas containing more than $25 \%$ villous structures were defined as adenomas with villous components. Non-neoplastic polyps included hyperplastic polyps and mucosal tags. ${ }^{12}$ Adenomas of particularly high risk of malignant transformation ${ }^{1323}$ were termed "high risk adenomas". They included those that were larger than $10 \mathrm{~mm}$ in diameter, those containing villous structures, and adenomas with severe dysplasia. A "significant finding" was defined as the discovery of a high risk adenoma and/or three or more adenomas irrespective of size or dysplasia or without villous components.

STATISTICAL ANALYSIS

Yates $\chi^{2}$ test was used to determine statistical significance of differences between proportions in frequency tables. Fisher's exact test was used when the expected frequencies were small. The Mann-Whitney test was used to compare means in demographic data. Medians are given with interquartile ranges (range comprising $50 \%$ of the observations, from the 25 th centile to the 75 th centile). A two sided $\mathrm{p}$ value less than 0.05 was considered statistically significant. NCSS-97 and SPSS-8.0 statistical software was used for analysis of the data.

ETHICS

The study was approved by the regional ethics committee and performed in accordance with the Helsinki Declaration.

\section{Results}

Of the 399 people enrolled as a control group in 1983, 358 were still alive in 1996. All but two, who had emigrated, were invited to an endoscopic examination. In all, 241 (68\%) attended; $19(8 \%)$ of the attendees preferred sigmoidoscopy. Polyps were found in 180 (75\%) subjects, and adenomas in $102(42 \%)$. The cleansing was regarded as satisfactory in 234 subjects $(97 \%)$. The caecum was intubated in $109(84 \%)$ men and $84(76 \%)$ women, $193(80 \%)$ subjects in all. The following sections present the results from the group of 193 attendees in whom the caecum was successfully intubated. In table 1 demographic data for this group are compared with the data for the group of attendees in whom the caecum 
Table 3 Distribution of polyps in the segments of colon in individuals in whom the caecum was intubated at screening colonoscopy

\begin{tabular}{llllllll}
\hline & Rectum & $\begin{array}{l}\text { Sigmoid } \\
\text { colon }\end{array}$ & $\begin{array}{l}\text { Descending } \\
\text { colon }\end{array}$ & $\begin{array}{l}\text { Transverse } \\
\text { colon }\end{array}$ & $\begin{array}{l}\text { Ascending } \\
\text { colon }\end{array}$ & Caecum & Total \\
\hline $\begin{array}{l}\text { Adenomas } \\
\quad \text { Total }\end{array}$ & $56(28)$ & $37(18)$ & $33(16)$ & $38(19)$ & $26(13)$ & $13(6)$ & $203(100)$ \\
$\quad 5 \mathrm{~mm}$ & $46(33)$ & $14(10)$ & $22(16)$ & $27(20)$ & $21(15)$ & $10(7)$ & $140(100)$ \\
$5-9 \mathrm{~mm}$ & $6(12)$ & $19(40)$ & $8(16)$ & $10(20)$ & $4(8)$ & $2(4)$ & $49(100)$ \\
$\quad \geqslant 10 \mathrm{~mm}$ & $4(29)$ & $4(29)$ & $3(21)$ & $1(7)$ & $1(7)$ & $1(7)$ & $14(100)$ \\
Moderate dysplasia & $6(15)$ & $8(20)$ & $9(22)$ & $13(32)$ & $2(5)$ & $3(7)$ & $41(100)$ \\
Severe dysplasia & 0 & $3(60)$ & $2(40)$ & 0 & 0 & 0 & $5(100)$ \\
Villous components & $3(18)$ & $7(41)$ & $2(12)$ & $3(18)$ & $1(6)$ & $1(6)$ & $17(100)$ \\
High risk adenoma* & $5(18)$ & $12(43)$ & $5(18)$ & $3(11)$ & $1(4)$ & $2(7)$ & $28(100)$ \\
Hyperplastic polyps & $233(78)$ & $28(9)$ & $3(1)$ & $20(7)$ & $10(3)$ & $5(2)$ & $299(100)$ \\
Mucosal tags & $108(73)$ & $14(10)$ & $9(6)$ & $12(8)$ & $2(1)$ & $3(2)$ & $148(100)$ \\
Histology unknown $\dagger$ & $20(83)$ & $2(8)$ & $1(4)$ & $1(4)$ & 0 & 0 & $24(100)$ \\
Total no of polyps & $417(62)$ & $81(12)$ & $46(7)$ & $71(11)$ & $38(6)$ & $21(3)$ & $674(100)$ \\
\hline
\end{tabular}

Adenomas are subdivided according to size, dysplasia and presence of villous components. Values represent numbers (\%).

*Adenoma $\geqslant 10 \mathrm{~mm}$ in diameter and/or villous components and/or severe dysplasia.

†No biological material obtained at biopsy.

was not intubated ( $\mathrm{n}=48)$. The only statistically significant difference between the two groups was in body mass index $\left(\mathrm{kg} / \mathrm{m}^{2}\right)$, with a slightly lower median value in the group in whom the caecum was not intubated.

POLYP DISTRIBUTION

In the group of 193 subjects in whom the caecum was intubated, polyps were found in 142 $(74 \%)$ and adenomas in $83(43 \%)$ (table 2$)$. Table 3 shows the distribution of polyps in the segments of the colon. An abundance of small polyps (1-2 $\mathrm{mm}$ ) was found in the rectum. A total of $205(74 \%)$ of these were sampled; 16 $(8 \%)$ were adenomas, $108(53 \%)$ were hyperplastic polyps, and $73(36 \%)$ were mucosal tags. Colorectal cancer was discovered in two subjects. About half of the adenomas were found in the rectum and sigmoid colon (table 3). Two thirds of high risk adenomas were also found at this location (table 3). Most of the adenomas detected $(189 ; 93 \%)$ were less than $10 \mathrm{~mm}$ in diameter (tables 3 and 4). Moderate or severe dysplasia was found in $46(23 \%)$ and villous components in $17(8 \%)$ of the adenomas (tables 3 and 4). Adenomas were exclusively localised in the rectum and sigmoid colon in 28 subjects $(15 \%$ of all with caecum intubated). In 36 (19\% of all with caecum intubated), the adenomas were exclusively localised proximal to the sigmoid colon, and, in eight of this group ( $4 \%$ of all with caecum intubated), high risk adenomas were discovered. Of these subjects, only one had a first degree relative with colorectal cancer. Only 22

Table 4 Size, presence of dysplasia and number of adenomas found in subjects in whom the caecum was intubated at screening colonoscopy (\% of total number of adenomas)

\begin{tabular}{|c|c|c|c|}
\hline & Women $(n=84)$ & $\operatorname{Men}(n=109)$ & Total $(n=193)$ \\
\hline Number of adenomas & 93 & 110 & 203 \\
\hline $\begin{array}{l}\text { Median (interquartile range) number } \\
\text { of adenomas per adenoma bearing } \\
\text { subject }\end{array}$ & $2(1-3)$ & $1(1-2)$ & $1(1-3)$ \\
\hline $\begin{array}{l}\text { Median (interquartile range) size of } \\
\text { adenomas (mm) }\end{array}$ & $4(3-5)$ & $3(3-5)$ & $4(3-5)$ \\
\hline Adenomas & & & \\
\hline$<5 \mathrm{~mm}$ & $62(67)$ & $78(72)$ & $140(69)$ \\
\hline $5-9 \mathrm{~mm}$ & $24(26)$ & $25(23)$ & $49(24)$ \\
\hline$\geqslant 10 \mathrm{~mm}$ & $7(8)$ & $7(6)$ & $14(7)$ \\
\hline Moderate dysplasia & $19(20)$ & $22(20)$ & $41(20)$ \\
\hline Severe dysplasia & $2(2)$ & $3(3)$ & $5(2)$ \\
\hline Villous components & $10(11)$ & $7(6)$ & $17(8)$ \\
\hline High risk adenomas $\star$ & $15(16)$ & $13(12)$ & $28(14)$ \\
\hline
\end{tabular}

^Adenomas $\geqslant 10 \mathrm{~mm}$ in diameter and/or villous components and/or severe dysplasia.
$(27 \%)$ of adenoma bearers had more than two adenomas (range 1-22) (fig 1). Fifteen ( $8 \%$ of all with caecum intubated) had adenomas solely proximal to the splenic flexure; in three of these ( $2 \%$ of all with caecum intubated), high risk adenomas were detected.

ADENOMAS LOCALISED IN THE PROXIMAL COLON COMPARED WITH THE DISTAL COLON

Table 5 gives the number of adenomas found in the proximal colon in relation to the number of polyps found in the rectosigmoid colon. Forty seven subjects had adenomas in the rectosigmoid colon; $19(40 \%)$ of these had proximal adenomas, compared with $36(25 \%)$ subjects with proximal adenomas in the group of 146 with no distal adenoma. This gives a relative risk (RR) of 1.6 (95\% confidence interval 2.6 to 1.0$)(p=0.06)$ of finding a proximal adenoma when a distal adenoma is present compared with finding a proximal adenoma with no distal adenoma detected. The relative risk of having proximal adenomas for subjects with distal adenomas larger than $5 \mathrm{~mm}$ compared with those with distal adenomas smaller than $5 \mathrm{~mm}$ was 1.5 (3.8 to 0.6$)$ ( $\mathrm{p}=$ $0.5)$. The relative risk of having a proximal adenoma with a distal adenoma of any size compared with having a proximal adenoma and a distal polyp of any kind was 1.3 (2.1 to $0.8)(p=0.3)$. Nine $(31 \%)$ of 29 men with adenomas in the rectosigmoid colon had adenomas in the proximal colon, whereas 22

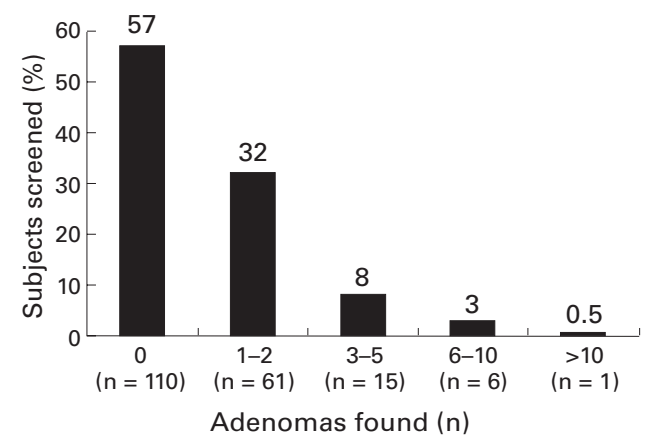

Figure 1 Percentage distribution of subjects with caecum intubated categorised according to number of adenomas found (none, 1-2, 3-5, 6-10 and more than 10). Total number of individuals in each category is given under the bars, which express percentage of individuals in each category. 
Table 5 Findings in proximal colon (caecum to and including the descending colon) in subjects in whom the caecum was intubated in the following categories according to findings in the rectosigmoid colon: those with their largest adenoma less than $5 \mathrm{~mm}$, those with their largest adenoma 5-9 $\mathrm{mm}$, those with the largest adenoma $>9 \mathrm{~mm}$, those with no adenoma, those with no polyp of any kind and those with polyps of any kind

\begin{tabular}{llll}
\hline Findings in rectosigmoid colon & $\begin{array}{l}\text { Adenoma in the } \\
\text { proximal colon }\end{array}$ & $\begin{array}{l}\text { High risk adenoma } \\
\text { in the proximal colon }\end{array}$ & $\begin{array}{l}\text { Significant findingt } \\
\text { in the proximal colon }\end{array}$ \\
\hline No polyp $(\mathrm{n}=77)$ & $20(26)$ & $5(6)$ & $9(11)$ \\
No adenoma $(\mathrm{n}=146)$ & $36(25)$ & $8(5)$ & $11(8)$ \\
Adenoma $<5 \mathrm{~mm}(\mathrm{n}=19)$ & $6(32)$ & 0 & $2(11)$ \\
Adenoma 5-9 mm $(\mathrm{n}=17)$ & $8(47)$ & $2(12)$ & $4(24)$ \\
Adenoma $\geqslant 10 \mathrm{~mm}(\mathrm{n}=11)$ & $5(45)$ & $1(9)$ & $1(9)$ \\
Adenoma any size $(\mathrm{n}=47)$ & $19(40)$ & $3(6)$ & $7(15)$ \\
Polyp of any kind $(\mathrm{n}=116)$ & $35(30)$ & $8(7)$ & $13(11)$ \\
\hline
\end{tabular}

Values represent subjects (\%).

*Adenoma $\geqslant 10 \mathrm{~mm}$ in diameter and/or villous components and/or severe dysplasia.

†High risk adenoma and/or three or more adenomas of any size, grade of dysplasia, or with or without villous components.

$(28 \%)$ of 80 men with no adenomas in the rectosigmoid colon had adenomas in the proximal colon (RR 1.1 (2.2 to 0.5$) ; p=0.9$ ). For women, the same figures were $10(56 \%)$ of 18 and $14(21 \%)$ of 66 (RR 2.6 (4.8 to 1.2$) ; \mathrm{p}=$ $0.01)$.

POSSIBLE MARKERS FOR ADENOMA PREVALENCE We did not find any associations between the presence of hyperplastic polyps and adenomas; $46(42 \%)$ of those without adenomas in their colon, $40(48 \%)$ of those with adenomas, and $13(36 \%)$ of those with only proximal adenomas had distal hyperplastic polyps $(\mathrm{p}=$ $0.4-0.6)$. No relations were found between having only proximally located adenomas and gender $(p=0.5)$, body mass index (over or under the 50 percentile) $(\mathrm{p}=0.2)$, age group (below or over 68 years) $(p=0.5)$, smokers versus non-smokers $(p=0.1)$, or having first degree relatives with colorectal cancer $(\mathrm{p}=$ 0.7 ).

Twenty eight (15\%) of the group of 193 subjects in whom the caecum was intubated had had an endoscopic large bowel examination other than the screening examination. Four subjects had had a total of eight adenomas removed during these examinations, the largest $7 \mathrm{~mm}$ in diameter, none of them showing more than moderate dysplasia. In all four, distal adenomas were detected at the screening.

\section{Discussion}

This study showed that almost half of the study population, 63-72 years of age, had adenomas, and that a substantial proportion had adenomas only proximal to the sigmoid colon. Autopsy studies have reported that $32-50 \%$ of women and $40-62 \%$ of men in the age group 60-80 years have adenomas. ${ }^{12} 141520$ Colonoscopic studies on age groups comparable with this study population found adenomas in $26 \%$ of women ${ }^{16}$ and $25-45 \%$ of men. ${ }^{16-19} 24$ The percentage of subjects with only proximal adenomas compares with previous endoscopic studies, which have shown that $13-70 \%$ of adenoma bearers have no distal adenoma. ${ }^{317-1924-26}$ The discrepancy in figures between autopsy studies and previous endoscopic studies may be partly due to autopsy study selection bias, as adenomas are associated with certain risk factors, such as athero- sclerosis, that predispose for early death. ${ }^{27}$ The use of a magnifying lens at autopsy and insufflation with air, stretching the mucosa and making minor lesions invisible at colonoscopy, may contribute to a higher pick up rate of minor lesions in autopsy studies. The bowel cleansing was good in almost all attendees, but even under these circumstances it has been estimated that $16-27 \%$ of polyps smaller than $5 \mathrm{~mm}$ and $5-17 \%$ of polyps $6-9 \mathrm{~mm}$ in size will be missed at a single endoscopic examination. ${ }^{28-30}$ This is a further indication that the true number of adenomas in a live normal population may indeed be higher than recorded in endoscopy studies and closer to the prevalence reported in autopsy studies.

Most endoscopic studies have recruited their subjects from health conscious groups such as doctors, dentists, and people attending special health care programmes. People with known colon pathology and gastrointestinal symptoms have been excluded. To preserve the status of being a random sample of the normal population, there were no exclusions from our study group. Thus several of the attendees had abdominal complaints, earlier diagnosed colorectal cancer, and first degree relatives with colorectal cancer (table 1). These risk factors may increase the prevalence of adenomas in our study group compared with other endoscopy studies.

The caecum was reached in $80 \%$ in our study. This is lower than reported in other studies, where the caecum was reached in $90-100 \%{ }^{31-34}$; this may partly be explained by the facts that $8 \%$ preferred a sigmoidoscopic examination and sedation was not given routinely. The demographic data for those in whom the caecum was intubated are comparable with the data for those in whom the caecum was not intubated. The slight difference in body mass index in the two groups can hardly be of any clinical importance and may be coincidental. The caecum was intubated in a lower proportion of women than men. Other investigators have also reported a lower success rate for women, ${ }^{34}{ }^{35}$ and this may be due to a more tortuous sigmoid colon and the shape of the pelvic outlet in women. Only eight adenomas had been removed from the study population before the screening examination, and this number would not have any impact on our results. The attendance rate for the screening examination was $68 \%$. Attendance for screening programmes is traditionally high in Norway, both mammography and cervical smear screening achieve $80 \%$ attendance rate in most counties. We do not know anything about those who declined to attend in our study. It has been shown that those who comply with screening examinations are a selected group of the population. ${ }^{36-38}$ It is also known that subjects who refuse to attend may be those with the highest risk of general somatic morbidity and hence may harbour more adenomas than the attendees. ${ }^{39}$ We were not able to find any factors (age, gender, smoking, atherosclerotic disease, or a first degree relative with colorectal cancer) predisposing to an adenoma distribution with only proximal adenomas. This may 
be due to the small numbers in our study and hence lack of statistical power. The figures do, however, indicate that differences in risk are so small that these factors should be of hardly any clinical use in organised screening within the present age group.

We did not find any association between hyperplastic polyps and proximal adenomas. Other investigators have found such an association. ${ }^{40-42}$ These studies have been criticised for their selection of study subjects and their retrospective design. ${ }^{43}$ Other investigators have more recently been unable to confirm these findings. ${ }^{43-46}$

Autopsy studies have shown a proximal shift in the distribution of adenomas in the colon with advancing age, with most adenomas found distally at ages below 60 and most in the proximal colon at age 70 years or older. ${ }^{13}{ }^{14} 20$ This is compatible with our results. To achieve a high attendance rate for a flexible sigmoidoscopy screening examination, it is probably wise to limit bowel cleansing to a small enema, for example a $240 \mathrm{ml}$ sorbitol enema, administered immediately before the examination. A flexible sigmoidoscopy examination immediately after a small enema may occasionally allow visualisation of the descending colon and even the transverse colon. One may therefore detect some of the adenomas proximal to the sigmoid/descending colonic junction.

In conclusion, this colonoscopic screening study of a normal population aged 63-72 years of age achieved a $68 \%$ attendance rate. With an adenoma prevalence of $43 \%$ and adenomas localised exclusively proximal to the sigmoid colon in $19 \%$ of attendees, endoscopic screening, if considered at all at this age, should probably be colonoscopy rather than flexible sigmoidoscopy. This would, however, require a high degree of acceptability in the population as in Telemark. An alternative strategy with flexible sigmoidoscopy and a baseline colonoscopy only in those who were found to have rectosigmoid adenomas would have missed eight subjects $(4 \%)$ with high risk adenomas and 11 subjects $(6 \%)$ with significant findings. This may be considered acceptable in populations with a low acceptance of colonoscopy, as the vast majority of proximal adenomas will not progress to clinical cancer within the life expectancy of this age group.

This study received financial support through grants from the Norwegian Cancer Society.

1 Vogelstein B, Fearon ER, Hamilton SR, et al. Genetic alterations during colorectal-tumor development. $N$ Engl f Med 1988;319:525-32.

2 Morson BC. The polyp-cancer sequence in the large bowel. Proc R Soc Med 1974;67:451-7.

3 Atkin WS, Morson BC, Cuzick J. Long-term risk of colorectal cancer after excision of rectosigmoid adenomas. $N$ Engl f Med 1992;326:658-62.

4 Bedenne L, Faivre J, Boutron MC, et al. Adenomacarcinoma sequence or "de novo" carcinogenesis? Cance 1992;69:883-8.

5 Winawer SJ, Zauber AG, Ho MN, et al. Prevention of colorectal cancer by colonoscopic polypectomy. $N$ Engl f Med 1993;329:1977-81.

6 Maule WF. Screening for colorectal cancer by nurse endoscopoists. N Engl f Med 1994;330:183-7.

7 Liebermann DA, Ghormely JM. Physician assistent in gastroenterology: Should they perform endoscopy? $A m \mathcal{F}$ Gastroenterol 1992;8:940-3.
8 Duthie GS, Drew PJ, Hughes MAP, et al. A UK training programme for nurse practitioner: flexible sigmoidoscopy and a prospective evaluation of the first UK trained nurse flexible sigmoidoscopist. Gut 1998;43:711-14

9 Selby JV, Friedman GD, Quesenberry CP, et al. A case-control study of screening sigmoidoscopy and mortality from colorectal cancer. N Engl f Med 1992;326:6537.

10 Gilbertsen VA. Proctosigmoidoscopy and polypectomy in reducing the incidence of rectal cancer. Cancer 1974;34: 936-9.

11 Thiis-Evensen E, Hoff SG, Sauar J, et al. Populationbased surveillance by colonoscopy: effect on the incidence of colorectal cancer. Scand f Gastroenterol 1999;34: 414-20.

12 Arminski TC, McLean DW. Incidence and distribution of adenomatous polyps of the colon and rectum based on 1000 autopsy examinations. Dis Colon Rectum 1964;7:24961

13 Eide TJ, Stalsberg H. Polyps of the large intestine in Northern Norway. Cancer 1978;42:2839-48.

14 Vatn $\mathrm{MH}$, Stalsberg $\mathrm{H}$. The prevalence of polyps of the large intestine in Oslo. An autopsy study. Cancer 1982;49:819-

15 Clark CJ, Collan Y, Eide TJ, et al. Prevalence of polyps in an autopsy series from areas with varying incidence of large bowel cancer. Int $\mathcal{F}$ Cancer 1985;36:179-86.

16 Rex DK, Lehman GA, Ulbricht TM, et al. Colonic neoplasia in asymptomatic persons with negative fecal occult blood tests: Influence of age, gender and family history. $\mathrm{Am}$ f Gastroenterol 1993;88:825-31.

17 Foutch PG, Mai H, Pardy K, et al. Flexible sigmoidoscopy may be ineffective for secondary prevention of colorectal cancer in asymptomatic, average-risk men. Dig Dis Sci 1991;36:924.

18 Lieberman D, Smith F. Screening for colon malignancy with colonoscopy. Am $\mathcal{F}$ Gastroenterol 1991;86:946.

19 Rex DK, Lehman GA, Hawes RH, et al. Screening colonoscopy in asymptomatic average-risk persons with negative FOBT. Gastroenterology 1991;100:64-7.

20 Chapman I. Adenomatous polypi of large intestine: incidence and distribution. Ann Surg 1963;157:223-6.

21 Hoff G, Vatn M, Gione E, et al. Epidemiology of polyps in the rectum sigmoid colon. Design of a population screening study. Scand f Gastroenterol 1985;20:351-5.

22 Jass JR, Sobin LH. Histological typing of intestinal tumors. In: WHO International Histological Classification of Tumors. Bn: Werlin: Springer Verlag, 1989:29-31.

23 Shinya H, Wolff WI. Morphology, anatomic distribution and cancer potential of colonic polyps. Ann Surg 1979;190: $679-83$.

24 Di Sario JA, Foutch G, Mai HD, et al. Prevalence and malignant potential of colorectal polyps in asymptomatic, average-risk men. Am f Gastroenterol 1991;86:941-5.

25 Lieberman DA, Smith FW. Frequency of isolated proximal colonic polyps among patients referred for colonoscopy. Arch Intern Med 1988;148:473-5.

26 Johnson DA, Gurney MS, Volpe RJ, et al. A prospective study of the prevalence of colonic neoplasms in asymptomatic patients with age-related risk. Am 7 Gastroenterol matic patients $190 ; 85$ : $969-74$.

27 Correa P, Strong JP, Johnson WD, et al. Atherosclerosis and polyps of the colon. Quantification of precursor of coronary heart disease. F Chronic Dis 1982;35:313-20.

28 Hoff G, Vatn M, Gjone E, et al. Epidemiology of polyps in the rectum and sigmoid colon. Endoscopic evaluation of size and localization of polyps. Scand $\mathcal{F}$ Gastroenterol 1985; 20;356-60.

29 Hixon LJ, Fennerty MB, Sampliner RE, et al. Prospective study of the frequence and size of polyps missed by colonoscopy. F Natl Cancer Inst 1990;82:1769-72.

30 Cutler CS, Clark DW, Lehman GA, et al. The colonoscopic miss rate for neoplastic polyps: a prospective study of backto-back colonoscopies. Gastrointest Endosc 1995;41:376.

31 Hofstad B, Vatn MH, Andersen SN, et al. Growth of colorectal polyps: redetection and evaluation of unresected polyps for a period of three years. Gut 1996;39:449-56.

32 Rogge JD, Elmore MF, Mahoney SJ, et al. Low-cost, office based, screening colonoscopy. Am F Gastroenterol 1994;89: 1775-80.

33 Squillace S, Berggreen P, Jaffe P, et al. A normal initial colonoscopy after age of 50 does not predict a polyp-free status for life. Am $\mathcal{F}$ Gastroenterol 1994;89:1156-9.

34 Waye JD, Bashkoff E. Total colonoscopy: is it always possible? Gastrointest Endosc 1991;37:152-4.

35 Church JM. Complete colonoscopy: how often? And if not, why not? Am f Gastroenterol 1993;89:556-60.

36 Maclean U, Sinfield D, Klein S, et al. Women who decline breast screening. $\mathcal{F}$ Epidemiol Community Health 1984;38. breast scre 278 .

37 Hayward RA, Shapiro MF, Freeman HE, et al. Who gets screened for cervical and breast cancer? Results from a new national survey. Arch Intern Med 1988;148:1177-81.

38 Farrands PA, Hardcastle JD, Chamberlain J, et al. Factors affecting compliance with screening for colorectal cancer. Community Medicine 1984;6:12-19.

39 Lindholm E, Berglund B, Haglin E, et al. Factors assosiated with participation in screening for colorectal cancer with feacal occult blood testing. Scand $\mathcal{F}$ Gastroenterol

40 Provenzale D, Martin ZZ, Holland KL, et al. Colon adenomas in patients with hyperplastic polyps. $\mathcal{F}$ Clin Gastroenterol 1988;10:46-9. 
41 Ansher AF, Lewis JH, Fleischer DE, et al. Hyperplastic colonic polyps as a marker for adenomatous colonic polyps.

42 Achkar E, Carey W. Small polyps found during fiberoptic sigmoidoscopy are markers for additional adenomas seen at colonoscopy. Gastroenterology 1991;100:564-6.

43 Brady PG, Straker RJ, McClave SA, et al. Are hyperplastic rectosigmoid polyps assosiated with an increased risk of proximal colonic neoplasms? Gastrointest Endosc 1993;39: $481-5$.
44 Rex DK, Smith JJ, Ulbright TM, et al. Distal colonic hyperplastic polyps do not predict proximal adenomas in asymptomatic average risk subjects. Gastroenterology 1992;102:

45 Zauber A, Winawer SJ, Diaz B, et al. The national polyp study (NPS): the association of colonic hyperplastic polyps and adenomas. Am $\mathcal{F}$ Gastroenterol 1988;83:1060.

46 Provenzale D, Garret JW, Condon SE, et al. Risk for colon adenomas in patients with rectosigmoid hyperplastic polyps. Ann Intern Med 1990;113:760-3. 